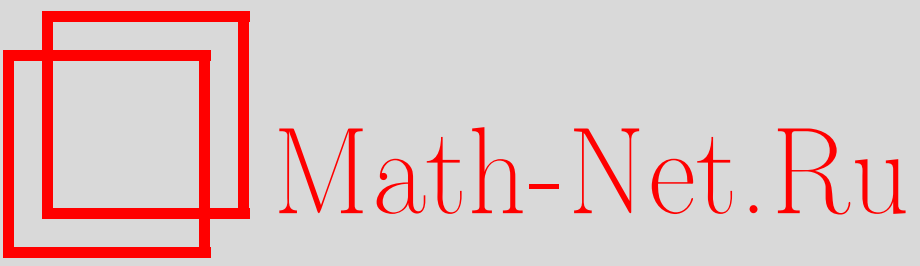

В. С. Владимиров, Р. И. Илькаев, Е. В. Малиновская, Ю. В. Прохоров, В. И. Родыгин, Ю. А. Романов, Б. А. Севастьянов, И. Д. Софронов, Ю. А. Трутнев, Л. П. Феоктистов, Д. В. Ширков, Николай Александрович Дмитриев (некролог), УМH, 2001, том 56, выпуск 2, 204-208

DOI: https://doi.org/10.4213/rm385

Использование Общероссийского математического портала Math-Net.Ru подразумевает, что вы прочитали и согласны с пользовательским соглашением http://www.mathnet.ru/rus/agreement

Параметры загрузки:

IP : 18.209 .158 .208

26 апреля 2023 г., 15:47:12 


\section{НИКОЛАЙ АЛЕКСАНДРОВИЧ ДМИТРИЕВ}

23 сентября 2000 года после тяжелой болезни на 76 году жизни скончался Николай Александрович Дмитриев, ведущий научный сотрудник ВНИИЭФ, выдающийся российский математик и физик, человек необычных способностей и необычной судьбы. В раскрытии его яркого таланта существенную роль сыграли семья, школа, Московский университет и коллектив Российского федерального ядерного центра ВНИИЭФ

Его дед был офицер, болгарин по национальности, который после известного выступления Христо Ботева осел в Польше. Его отец родился в 1893 году и тоже стал офицером. Окончил кадетский корпус в г. Полоцке и военное артиллерийское училище в Петербурге. Участвовал в первой мировой войне. Во время гражданской войны служил сначала в белой, а затем в Красной армии. После демобилизации

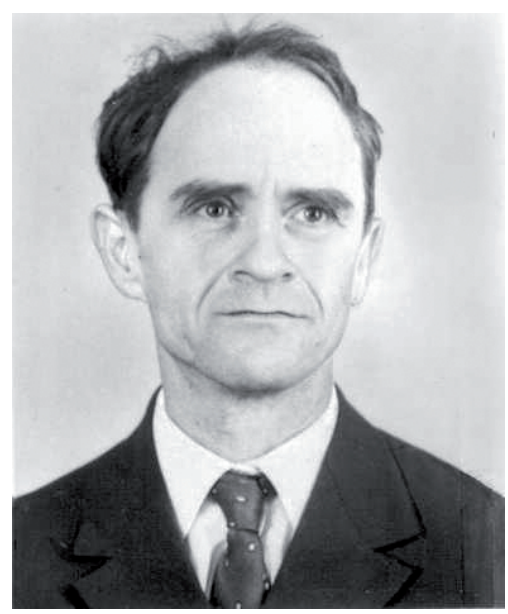
работал техником в различных учреждениях Москвы.

Мать Николая Александровича, Валентина Марковна (Горькавая), родилась в 1897 году в г. Таганроге в семье хозяина небольшого магазина. Окончила гимназию, преподавала музьку и в 1923 году вышла замуж. 27 декабря 1924 года у нее родился старший сын Коля.

В 1927 году отец Коли был арестован и выслан на север Тюменской области. После окончания срока ссылки отца в 1930 году семья обосновалась в г. Тобольске. Здесь и обнаружились необычайные способности Коли. Он сам научился читать по кубикам в возрасте до четырех лет. В шесть лет он уже читал свободно и понимал научно-популярные книги, которые его интересовали. До девяти лет родители учили Колю сами дома по курсу школы математике, физике, язькам и другим предметам. Друзья отца о способностях его сына сообщили в Облоно. Из Свердловска (ныне Екатеринбург) приехал инспектор, который, убедившись в высокой одаренности Коли, организовал переезд семьи в Свердловск. Вскоре Коля был отправлен в Москву, где его смотрела комиссия во главе с Наркомом просвещения РСФСР А. С. Бубновым при участии Н. К. Крупской. Выяснилось, что Коля уже знает весь курс математики средней школы. В связи с этим Колю определили в 4-й класс опытно-показательной школы им. Радищева и организовали с ним индивидуальные занятия по математике и французскому язьку, назначили большую стипендию (500 рублей, что было больше зарплаты отца). Семье Коли были выделены три комнаты в новой пятикомнатной квартире в центре города. В московских газетах того времени о Коле писали как о явлении, которое бьвает "раз в сто лет".

Школу Коля окончил в 1939 году и в возрасте 14 лет поступил в Московский университет на механико-математический факультет. В начале Отечественной войны отец ушел в ополчение и безвестно погиб при защите Москвы. Мать с младшими детьми эвакуировалась в Башкирию. Коля эвакуировался из Москвы вместе с университетом сначала в Казань, а затем в Ашхабад. 
Там Коля, будучи подростком, от недоедания и неустроенности, тяжело заболел. От гибели его спасли энергичные действия руководителей университета. В 1942 году университет был переведен в Свердловск, а в 1943 году вернулся в Москву. В 1944 году вернулась в Москву и мать Коли с младшими детьми.

Николай Александрович окончил университет в 1945 году и был зачислен в аспирантуру университета. Свою первую научную работу о характеристических корнях стохастических матриц он выполнил совместно с Е. Б. Дынкиным [1], [3]. Затем он был переведен в аспирантуру в МИАН им. В.А. Стеклова, где его руководителем был всемирно известньй математик академик А. Н. Колмогоров, совместно с которым Н. А. Дмитриев опубликовал в 1947 г. свою вторую работу [2].

В 1946 году Н. А. Дмитриев, в возрасте 22 лет и в должности младшего научного сотрудника, был привлечен к урановому проекту и переведен в группу Я.Б. Зельдовича в Институт химической физики. В 1948 году эта группа была переведена из Москвы в город Саров, в Конструкторское бюро № 11 Лаборатории № 2 АН СССР. Как известно, со временем КБ-11 превратилось в Российский федеральный ядерный центр - ВНИИЭФ, где создавалось советское атомное и водородное оружие. Здесь, в окружении самых выдающихся ученых страны, таких как Ю. Б. Харитон, Я. Б. Зельдович, А. Д. Сахаров, Д. А. Франк-Каменецкий, Е. И. Забабахин, Н. Н. Боголюбов, И.Е. Тамм, яркий талант и обширные знания Н. А. Дмитриева получили свое дальнейшее развитие и применение. Николай Александрович становится одним из основных созидателей грозного ядерного оружия. Руководители КБ-11 в своих аттестациях считали Н. А. Дмитриева одним из самых одаренных, квалифицированных и ценных ученых в КБ-11.

Для успеха испытаний первых атомных бомб при отсутствии ЭВМ были важны уникальные аналитические расчеты Н.А. Дмитриева. Например, им была разработана теория возмущения для критических сборок; развита теория неполного атомного взрыва (совместно с Я. Б. Зельдовичем и Д. А. Франк-Каменецким); впервые у нас было показано существование логарифмической особенности плотности нейтронов на границе двух сред; разработана теория прямого определения в лабораторных условиях на реакторе, по методу запаздывающих совпадений, фундаментальной для развития ядерного взрьва величины ламбда.

Эта идея стала событием в научной жизни института. Для измерения эффекта была организована специальная бригада под руководством Ю.Б. Харитона, состоящая из теоретиков и экспериментаторов (Я.Б. Зельдович, Г.Н. Флеров, Д. А. Франк-Каменецкий, В. Ю. Гаврилов, Д.П. Ширшов, А.И. Веретенников). Самое удивительное для участников опытов было то, что результаты измерений четко легли на кривые, предсказанные Николаем Александровичем.

В 1952 году Н. А. Дмитриевьм была разработана методика расчета растворных критических систем, предложенных Г. Н. Флеровым в целях экономии дефицитных делящихся материалов. Он был участником первых опытов с такими системами, которые проводились лично И. В. Курчатовьм и Г.Н. Флеровым на комбинате "Маяк". Эти опыты послужили основой для создания в стране импульсных ядерных реакторов, используемых и сейчас для исследований радиационной стойкости военной техники.

В том же году Н.А. Дмитриев совместно с Ю. А. Трутневым исследовал обратный комптонэффект при упругом рассеянии квантов на электронах в плазме. Результаты этой работы были важны для более полного понимания физики взрыва термоядерных систем.

В 1954 году Н. А. Дмитриевьм, совместно с Я. Б. Зельдовичем, Д. А. Франк-Каменецким и В.Н. Родигиным, было показано, что лучшим способом защиты от страшного атомного оружия, транспортируемого самолетом, является высотный ядерный взрьв небольшой мощности. Выделяющиеся при этом нейтроны летят в разреженной атмосфере на большое расстояние и поражают атомный заряд, имеющий специфическую чувствительность к нейтронам. Это дало толчок для создания в стране зенитной атомной управляемой ракеты, а затем и системы ПВО.

В 1955 году Н. А. Дмитриев назначается начальником математического отдела, и работает в этом качестве до конца 1959 года. Его идеи и начинания этого периода сыграли существенную роль в дальнейшем развитии ядерного оружия и в становлении современной вьчислительной математики. Как известно, работа математиков ВНИИЭФ проходила в тесном контакте с ОПМ МИАН СССР, где работали такие выдающиеся математики как В. С. Владимиров, И. М. Гельфанд, С. К. Годунов, А. А. Самарский, А. Н. Тихонов, Н. Н. Яненко во главе с директором отде- 
ления, а затем и института президентом академии наук СССР М.В. Келдышем. Эти ученые с большим уважением относились к яркому таланту и трудам Н. А. Дмитриева.

Как известно, в тот период происходило бурное развитие ядерного оружия в стране в связи с переходом на новую бинарную схему ядерных зарядов и размещением этих зарядов на межконтинентальных ракетах и других носителях. Актуальным для математиков перед мораторием ядерных испытаний стал массовый "авральный" счет на ЭВМ, специфических для данного типа зарядов задач и, в первую очередь, одномерных задач газодинамики с теплопроводностью, решение которых было необходимым для симметризации работы вторичного узла заряда.

В этой связи существовавшая тогда программа И-33, разработанная в ОПМ, была существенно усовершенствована сначала Н. А. Дмитриевым, а затем И. Д. Софроновым в целях устранения аварийных остановок счета. Далее программа была развита до программного комплекса И-333, содержащего в себе все основные принципы построения современных комплексов программ: модулярность, наличие язька описания начальных данных, языка описания результатов счета, библиотек стандартных веществ, библиотек уравнений состояния, граничных условий и т. д.

По этим новым принципам Н. А. Дмитриев сам лично составил программу для ЭВМ “Стрела". При этом он одновременно держал в памяти и увязьвал между собой значительно более длинные тексты программы, чем любой классньй программист. Поразительньм было то, что эта сложная и необычная программа сразу же запустилась на ЭВМ, безо всякой предварительной отладки. Это было чудом. Ничего подобного специалисты ранее не видели!

Далее необходимо сказать о разработке Н.А. Дмитриевьм совместно с И. Д. Софроновьм и Е. В. Малиновской методики и разностной схемы “Д” расчета двумерных задач газовой динамики в лагранжевых переменных. Это была одна из первых в стране на 1956-57 годы двумерных программ, с помощью которой был выполнен на ЭВМ "Стрела" ряд интересных и уникальных для того времени расчетов. В настоящее время программа “Д” широко применяется и развивается.

Для успеха испытаний первых термоядерных бомб важными были также разработка Н.А. Дмитриевым методов численного расчета уравнения состояния конструкционных материалов в экстремальных условиях ядерного взрыва, методов численного решения нейтронных задач методом Монте-Карло и многое другое.

В конце 1959 года Н.А. Дмитриев переходит в теоретическое подразделение института и работает сначала старшим научным сотрудником, а с 1967 по 1986 год начальником теоретического отдела. Его деятельность в этот период расширилась. В среде физиков-теоретиков и математиков всех рангов он чаще стал выступать в качестве консультанта. Эти контакты стимулировали появление в институте ряда новых фундаментальных работ [9], [10], [15], [17] и др.

Отдельно надо сказать о работе [8] Н. А. Дмитриева этого периода, в которой им была получена, прямо из волновых функций стационарного состояния системы, точная формула для определения холодного давления в кристалле. В этой формуле нет стороннего вклада в давление кинетических флуктуация электронов и их электромагнитного взаимодействия внутри ячеек. Точное решение - это редкий случай в большой науке. Такой результат безусловно является классическим в области статистической физики.

Поражает широта научных интересов Н.А. Дмитриева и та легкость, с которой он осваивал новые для себя отрасли знаний: газовая динамика, ядерная физика, квантовая механика, термодинамика, вычислительная математика и многое другое.

За свой самоотверженньй труд и большой творческий вк лад в создании ядерных и термоядерных зарядов в стране Н. А. Дмитриев был дважды награжден орденом "Трудового Красного Знамени" (1949 и 1951 г.г.), орденом Ленина (1961 г.), и дважды был удостоен Государственной премии СССР (1951 и 1972 гг.). В 1953 году он блестяще защитил кандидатскую диссертацию. При сдаче кандидатских экзаменов он удивил комиссию знанием четырех иностранных язьков: французского, немецкого, английского и польского.

В жизни Николай Александрович был удивительно скромным, бескорыстным и чистым человеком. В своих политических суждениях отличался принципиальностью. За "неправильные" высказьвания получил три строгих выговора, которые потом были сняты, так как его политические предвидения со временем сбывались. 
Очень любил свою семью. Свой отпуск он обычно проводил в кругу семьи на природе в туристических походах по глухим местам или в путешествиях на байдарках по мальм рекам.

Наш долг, долг тех, кто его хорошо знал и многие годы с ним вместе работал, - воздать должное, для увековечивания памяти об этом уникальном и дорогом для нас человеке. Человеке, который является гордостью российской науки.

В. С. Владимиров, Р.И. Илькаев, Е. В. Малиновская, Ю. В. Прохоров, В.И. Родыгин, Ю.А. Романов, Б. А. Севастьянов, И. Д. Софронов, Ю. А. Трутнев, Л. П. Феоктистов, Д. В. Ширков

\section{СПИСОК НАУЧНЫХ РАБОТ Н. А. ДМИТРИЕВА}

[1] О характеристических числах стохастических матриц // Докл. АН СССР. 1945. Т. 49. С. 159-162 (совм. с Е. Б. Дынкиным)

[2] Ветвящиеся случайные изопроцессы // Докл. АН СССР. 1947. Т. 56. № 1. С. 4 (совм. с А.Н. Колмогоровым)

[3] Характеристические корни стохастических матриц // Изв. АН СССР. Сер. матем. 1946. Т. 10. С. 167-184 (совм. с Е. Б. Дынкиньгм)

[4] Решение задачи об осесимметричном движении газа с ударной волной // Отчет ОПМ МИАН СССР, 1954 (совм. с М. В. Келдышем, К. И. Бабенко, И. М. Гельфандом, О. В. Локуциевским, Н. Н. Ченцовым); // Избранные труды М. В. Келдыша. М.: Наука, 1985

[5] Физика высоких давлений и температур (курс лекций) // архив ВНИИЭФ, 1956. инв. № 01/ 678 (совм. с Г.М. Гандельманом)

[6] Неадиабатические пульсации звезд при постоянном показателе адиабаты // Докл. АН СССР. 1956. Т. 110. № 6. С. 949-951 (совм. с М. И. Феодоритовой, Д. А. Франк-Каменецким)

[7] The equation od state of a crystal at zero temperature // Soviet physic jetp. 1962. V. 15. № 3 . P. 539-542

[8] Об уравнении состояния кристалла при нулевой температуре // ЖЭТФ. 1962. Т. 42. № 3. C. $772-776$

[9] Особенности статистических решений уравнений тяготения // Вопросы космогонии. 1963. T. 9. С. 254-264 (совм. с С. А. Холиным)

[10] Энергия случайного движения в расширяющейся вселенной // ЖЭТФ. 1963. Т. 45. № 4. С. $1150-1155$ (совм. с Я.Б. Зельдовичем)

[11] О количественном критерии ферромагнетизма // ЖЭТФ. 1970. Т. 59. №6. С. 2016-2024 (совм. с Г.М. Гандельманом, М. $\Phi$. Сарры)

[12] Оценка корреляционных эффектов в узких энергетических полосах // ЖЭТФ. 1973. Т. 64. С. 1973-1980 (совм. с А. К. Житником, М. Ф. Сарры)

[13] О роли корреляционных эффектов в уравнении состояния металла при нулевой температуре // ЖЭЭФ. 1975. Т. 69. № 1. С. 234-239 (совм. с А. К. Житником, М. Ф. Сарры)

[14] Методика расчета двумерных нестационарных задач газовой динамики в переменных Лагранжа / / Препринт № 59. М.: ИПМ АН СССР, 1976 (совм. с И. Д. Софроновым, Л. В. Дмитриевой, Е. В. Малиновской)

[15] О высокотемпературной асимптотике термодинамических величин в модели Хартри-Фока // Сборник "Рапорт" ЦНИИ Атоминформа. № 2, 1976 (совм. с В. П. Копьшевым)

[16] Методика расчета двумерных нестационарных задач газовой динамики в переменных Лагранжа // Прейскурант ИПМ. № 59, 1976. С. 1-52 (совм. с И. Д. Софроновым, Л. В. Дмитриевой, Е. В. Малиновской)

[17] Давление в металлах в приближении Хартри-Фока // ФТТ. 1977. Т. 19. № 11. С. 3332-3338 (совм. с А. И. Воропиновым, Г. М. Гандельманом, В. Г. Подвальным)

[18] Междуячеечная обменная энергия металла в приближении Хартри-Фока // ФТТ. 1979. Т. 21. С. 2835-2837 (совм. с М. Ф. Сарры, Н. М. Чулковым)

[19] Корреляционные эффекты и ферромагнетизм // ФММ. 1979. Т. 48. № 2. С. 240-250 (совм. с Г.М. Гандельманом, А. К. Житником, М. Ф. Сарры) 
[20] Методика расчета нестационарных двумерных задач газовой динамики в Лагранжевых координатах // Теоретические основы и конструирование численных алгоритмов задач математической физики / ред. К. И. Бабенко. М.: Наука, 1978. С. 75-200 (совм. с И. Д. Софроновым, Л. В. Дмитриевой, Е. В. Малиновской)

[21] Особенности строения электронных спектров редких металлов при высоких давлениях // ФММ. 1981. Т. 76. С. 76-81 (совм. с Л. В. Альтшулером, А. И. Воропиновым, Г. М. Гандельманом, В.Г. Подвальным)

[22] Об одной неаккуратности в "Термодинамике" Базарова // Изв. вузов. Физика. Издание Томского ун-та. 1981. № 3. С. 103 (совм. с М. Ф. Сарры)

[23] Влияние внутриячеечного обменного взаимодействия электронов на энергетические спектры и уравнение состояния твердых тел при $T=0$ // ФММ. 1981. Т. 52. № 1. С. 28-35 (совм. с В. Г. Подвальным)

[24] Методика расчета одномерных многообластных задач высокотемпературной газовой динамики / / Вопросы атомной науки и техники. Серия: Методики и программы численного решения задач математической физики. 1983. № 3/14. С. 3-8 (совм. с И. Д. Софроновым, Б. П. Тихомировым)

[25] Методика численного решения двумерных задач нестационарного переноса излучения, обладающих симметрией вращения // Вопросы атомной науки и техники. Серия: Методики и программы численного решения задач математической физики. 1983. № 3/14. С. 33-35 (совм. с С.В. Баженовым, Л. М. Диборовой, К. С. Исаевой, П. А. Перепелкиным)

[26] Features of static solutions of the eqyations of gravitation // "In the intermission ... " Collected Works on Research into the Essentials of Theoretical Physics in Russian Nuclear Center Arzamas-16 / ed. Yu. A. Trutnev. Singapore: World Scientific, 1999. P. 18-26 (with S. A. Kholin)

[27] The equation of a crystal at zero // "In the intermission ..." Collected Works on Research into the Essentials of Theoretical Physics in Russian Nuclear Center Arzamas-16. Singapore: World Scientific, 1999. P. 208-214 (with Yu. A. Trutnev (ed. )) 